This is a self-archived - parallel published version of this article in the publication archive of the University of Vaasa. It might differ from the original.

\title{
The varying roles of governance mechanisms on ex-post transaction costs and relationship commitment in buyer-supplier relationships
}

Author(s): Shahzad, Khuram; Ali, Tahir; Takala, Josu; Helo, Petri; Zaefarianc, Ghasem

Title: The varying roles of governance mechanisms on ex-post transaction costs and relationship commitment in buyersupplier relationships

Year: $\quad 2018$

Version: Accepted manuscript

Copyright (C) 2017 Elsevier, Creative Commons Attribution NonCommercial No Derivatives License

Please cite the original version:

Shahzad, K., Ali, T., Takala, J., Helo, P, \& Zaefarianc, G, (2018). The varying roles of governance mechanisms on ex-post transaction costs and relationship commitment in buyersupplier relationships. Industrial marketing management 71 , 135-146. https://doi.org/10.1016/j.indmarman.2017.12.012 


\section{Title page}

Khuram Shahzad (Corresponding author)

Department of Production, Wolffintie 34, 65200 Vaasa khuram.shahzad@uva.fi

University of Vaasa, Finland +358403739946

\section{Dr. Tahir Ali}

Department of Marketing, Wolffintie 34, 65200 Vaasa tahir.ali@uva.fi

University of Vaasa, Finland +358458480333

Professor Josu Takala

Department of Production, Wolffintie 34, 65200 Vaasa josu.takala@uva.fi

University of Vaasa, Finland +358294498321

Professor Petri Helo

Department of Production, Wolffintie 34, 65200 Vaasa petri.helo@uva.fi

University of Vaasa, Finland +358294498551

Dr. Ghasem Zaefarian

Leeds University Business School

G.Zaefarian@,leeds.ac.uk

University of Leeds, United Kingdom +441133433233 
The varying roles of governance mechanisms on ex-post transaction costs and relationship commitment in buyer-supplier relationships

\begin{abstract}
Inter-firm relationship governance is becoming increasingly fragmented and complex in industrial marketing and management. There is a need to develop an integrative framework, which describes the nature of the relationship (complementary or substitutes) between economic and sociological governance mechanisms, and their relative effectiveness in explaining ex-post transaction costs and relationship commitment. Building on transaction cost economics (TCE) and social exchange theory (SET), we investigate the varying roles of economic (i.e., contract completeness and symmetric dependence) and sociological (i.e., trust and communication) governance mechanisms. The deductive-nomological framework is tested by employing a nonparametric technique (i.e., partial least squares - PLS) to structural equation modeling (SEM) and semi-partial correlation. The analysis of data from 170 buyer-supplier relationships established by Finnish SMEs indicates that sociological mechanisms function as substitutes with contractual governance and complementary with symmetric dependence in relation to ex-post transaction costs and relationship commitment. Further, economic governance mechanisms have a more effective role in minimizing ex-post transaction costs, whereas sociological governance mechanisms are more powerful in enhancing relationship commitment.
\end{abstract}

Keywords: Relationship governance mechanisms; ex-post transaction costs; relationship commitment; buyer-supplier relationships; structural equation modeling 


\section{Introduction}

Minimizing transaction costs and maximizing relationship commitment have become the central research phenomena in inter-firm relationship management. Transaction cost is defined by Williamson (1985) as all of the ex-ante and ex-post contracting, monitoring and enforcement costs connected with conducting exchange activities between firms (Gulbrandsen et al., 2017). Relationship commitment, on the other hand, is considered as a central ingredient of the relationship marketing model affecting the behavior of partners (Shi et al., 2011), and involves a need to develop and maintain a stable relationship (Anderson \& Weitz, 1992). However, the uncertainty of buyers and suppliers regarding the expectations whether the counterpart abandons opportunistic behavior and acts cooperatively in bargaining and negotiation is an inevitable dilemma in relationship exchange (Gorton et al., 2015). Similarly, incomplete contracts, distrust, asymmetric information sharing and interdependence, differences in objectives as well as unanticipated changes in the market are depicted as negative forces influencing transaction costs and relationship commitment.

Governance, therefore, becomes pivotal in buyer-supplier relationship development (Liu et al., 2017a; Luo et al., 2015). Prior inter-firm governance literature suggests that, in order to achieve joint objectives, firms need to erect appropriate governance factors, namely; economic and sociological mechanisms (e.g., Bai et al., 2016; Yang et al., 2017; Liu et al., 2009), rooted in transaction cost economics (TCE) and social exchange theory (SET). Economic mechanisms, in line with TCE, include certain governance factors, firms emplaced to avoid transactional uncertainties through adequate structural implications. Whereas sociological mechanisms as SET factors help to govern inter-firm relationships by developing a cooperative environment between firms (Liu et al., 2009; Liu et al., 2017a). 
Although prior empirical research has extensively documented the effective roles of governance mechanisms, it remains in limited context of opportunism mitigation (e.g., Liu et al., 2009; Luo et al., 2015), relationship performance (e.g., Yang et al., 2016; Liu et al., 2017a) and conflict management (e.g., Yang et al., 2017; Lee et al., 2017; Lumineau \& Henderson, 2012). A growing number of empirical studies demonstrate that economic structure of relationship exchange is sociologically embedded (e.g., Granovetter, 2005; Dyer \& Chu, 2011). Some past empirical studies have investigated only a few governance mechanisms i.e. trust and transaction-specific investments, their roles remained in isolation in explaining governance cost (Dyer \& Chu, 2003; Corsten \& Felde 2005; Bharadwaj \& Matsuno 2006) and commitment (Shi et al., 2011; Chang et al., 2012). Moreover, several recent studies on inter-firm have called for a systematic research on distinct roles of relationship governance mechanisms in relation to transaction costs and relationship commitment in different types of buyer-supplier relationships (e.g., Burkert et al., 2012; Gulbrandsen et al. 2017; Liu et al., 2017a). Therefore, researchers have different opinions as well as they found conflicting empirical results on whether these mechanisms function as complementary (Van der Valk et al., 2016; Liu et al., 2009) or substitutive forces (Wuyts \& Geyskens, 2005; Li et al., 2010). On the other hand, the relative effectiveness of these mechanisms is characterized by nuanced understanding of different transaction objectives driving governance structures, which is missing in the literature.

Different governance structures are required for different transaction objectives in governing relationship exchange (Burkert et al., 2012). Better understanding of relationship outcomes and collaboration goals drive managers to analyze which governance mechanism is more crucial for a particular task (Yang et al., 2016). Therefore, the varying roles of economic and sociological governance mechanisms in minimizing ex-post transaction costs and maximizing relationship 
commitment has yet to be addressed. Such mixed evidence and conflicting views on complementary-substitutive perspective and relative effectiveness of governance mechanisms, therefore, necessitates further investigation of the phenomenon. Thus, an interesting question now is concerned with whether sociological governance mechanisms function as complementary or substitutes with contractual governance and symmetric dependence respectively in minimizing expost transaction costs and fostering relationship commitment.

To fill these gaps and provide further insights, this study aims to address the concerns mentioned above. Therefore, this study contributes to the industrial marketing and management literature by portraying a comprehensive picture of relative effectiveness, as well as the joint use of both economic (i.e., contract completeness and symmetric dependence) and sociological (i.e., trust and communication) governance mechanisms influencing ex-post transaction costs and relationship commitment. Further, it develops and empirically tests a nomological framework by employing a nonparametric technique (i.e., PLS) to SEM and semi-partial correlation. The empirically comparative investigation in concurrent examination of these two effects alongside will support us in understanding the relative influence of varying governance mechanisms in order to manage successful buyer-supplier relationships. Such techniques provide firms the opportunities to evaluate the relative effectiveness of various governance mechanisms (Yang et al., 2016). The study's findings generally support our argument that economic mechanisms are relatively more effective at minimizing ex-post transaction costs, while sociological governance mechanisms are more effective at maximizing relationship commitment. Further, when sociological mechanisms interact with contract completeness and symmetric dependence, interesting findings emerge related to their complementary and substitutive nature. 


\section{Theoretical background and hypotheses}

\subsection{Governance mechanisms in buyer-supplier relationships}

Governing successful buyer-supplier relationships in a systematic way is found to be pivotal in enhancing beneficial outcomes and stability (Liu et al., 2009; Liu et al., 2017a, 2017b). The main question, therefore, is how to design an effective governance structure where both parties are fully devoted to fulfilling their common business objectives (Luo et al., 2015). For this reason, several recent studies have highlighted the significance of multiple governance mechanisms (e.g., Bai et al., 2016; Liu et al., 2009; Yang et al., 2017). These mechanisms are mainly found embedded in both economic and sociological mechanisms (Liu et al., 2017a, 2017b).

\subsubsection{Economic governance mechanisms}

Economic governance mechanisms are explained in terms of economic rational organizational measures, which support managing, monitoring and harmonizing partners' behaviors in relationship exchange (Williamson, 1985; Liu et al., 2009). Contract completeness and symmetric dependence, as economic mechanisms, demonstrate mutually specified contractual clauses and relationship specific investments (Brown et al., 2000; Liu et al., 2017b). Contractual governance is albeit ubiquitous and offers an institutional framework, regulating course of relationship exchange (Luo, 2009; Liu et al., 2017b), it varies in the level of completeness, complexities (Crocker \& Reynolds, 1993), rigidity, and flexibility (Sande \& Haugland, 2015). Several researchers have maintained that contracts will always be incomplete due to inevitable unpredictability (Crocker \& Reynolds, 1993; Luo, 2009). Therefore, a relatively complete contract minimizes the boundary spanners' uncertainty and risks of opportunisms. A well-defined contract is considered as a comprehensive instrument (i.e., explaining rules and regulations, rights and obligations of both parties) for safeguarding specific assets against opportunism (Luo, 2009; Liu 
et al., 2017b). Moreover, the level of completeness in a contract stipulates the extent to which contractual terms and future contingencies are specific and detailed. Term specificity highlights each partner' rights, duties and responsibilities in order to organize and manage the relationship whereas contingency adaptability concerns the contractual response to future problems, conflicts and contingencies (Luo, 2002; Reuer \& Arino, 2007). Hence, this level of contact completeness delineate exchange substance and structure resulting in maximum pay-off.

Whereas symmetric dependence entails both relationship partners to invest idiosyncratically in physical and human assets that are less valuable to alternative uses (Kumar et al., 1995; Ali \& Larimo, 2016; Khalid \& Ali, 2017). These co-specialized investments create interdependence between partners, prior research, therefore argued that symmetric interdependence is a product of both partners' equal dependence on each other by investing jointly in a relationship (e.g., Kumar et al., 1995; Wu \& Wu, 2015). On the other hand, asymmetric dependence effects on coercive power of less dependent partner to exploit, and creates prospects for opportunism and conflict (Liu et al., 2017b; Shen et al., 2017). Therefore, high level of symmetric dependence enhances the joint motivation of forbearance and relational embeddedness between partners, and discourages individual private goal seeking by binding and locking firms to a particular course of action (Young-Ybarra \& Wiersema, 1999; Schmitz et al., 2016).

\subsubsection{Sociological governance mechanisms}

Sociological governance mechanisms are defined as socially embedded organizational measures in economic activities, which help in managing, monitoring and organizing relationship exchange (Granovetter, 2005; Liu et al., 2017b). Based on existing research, we categorize two sociological governance mechanisms (i.e., trust and communication), which underlie the impact of relational ties between buyer and supplier. Trust is a non-contractual mechanism and defined as the 
willingness to trust or confidence that a partner holds about the other partner's reliability, benevolence, and integrity (Zaheer et al., 1998). Prior research on relationship trust has distinguished different conceptualization and presented influential perspectives. Such as, Dyer and Chu (2011) highlighted trust as the level of confidence of a relationship partner for other partner's fair behavior of not exploiting its vulnerabilities. On the other hand, Williamson (1993a) presented important economic perspective of trust and distinguished between calculative, personal and institutional trust. Calculative trust includes "relational" frame of trust nurtured by mutual hostages and considered as "risk". Personal trust implicates in personal relationships and portrays as noncalculative. Institutional trust refers to social and organizational embeddedness and appears also as being calculative. Both the relational calculation and the "leap of faith" comprise trust in business relationships. While effective communication, is considered as a useful tool in developing collaboration, integration and cooperation between relationship partners (Kim \& Chai, 2017). It refers to the bilateral expectation of formal and/or informal sharing of meaningful and timely information exchange between relationship partners (Wang et al., 2016). Building on SET, we conceptualize that communication strengthens the confidence of both parties in a relationship in terms of the availability of particular information (Yang et al., 2017) that is timely, and offered frequently, formally and informally (Hung \& Lin, 2013).

In this study, both economic and sociological mechanisms are anticipated to mitigate ex-post transaction costs and to enhance relationship commitment. Transaction costs include the costs involved in order to attain jointly acceptable agreement (Zaheer et al., 1998; Luo et al., 2015). Notably, ex-post transaction costs contain the negotiation time and efforts required to define effective arrangements and to determine divisions of costs and benefits (Gulbrandsen et al., 2017). On the other hand, relationship commitment is defined as relationship partners' confidence 
regarding the importance and efforts of maintaining the long-term relationship by willingly making short-term sacrifices. We conceptualize relationship commitment as a sense of loyalty and the continuity of business for a longer time to strengthen the relationship (Anderson \& Weitz, 1992; Tellefsen, 2002).

\subsection{Economic governance mechanisms, transaction costs, and relationship commitment}

The level of contractual completeness makes the relationship contractually explicit by mitigating partners' anxiety and exchange hazards (Wuyts \& Geyskens, 2005), and functions as a safeguard against higher transaction costs. Previous research has argued that detailed contractual terms and clauses, as comprehensive instruments, effectively regulate behavioral boundaries, operational risks and opportunism, thus, developing relationship commitment and cost performance (Liu et al., 2009; Yang et al., 2017). Dyer and Chu (2003) argue that contracts minimize ex-post monitoring and enforcement costs because all the expectations and obligations are explicitly indicated during the contracting phase. On the other hand, some authors (e.g., Crocker \& Reynolds, 1993) suggest that contractual completeness is the optimal balance between ex-ante (e.g., writing the contract) and ex-post transaction costs (e.g., managing disputes). The former increases when environmental uncertainty increases, the latter increases when the risk of opportunism increases. Therefore, relatively more complete contract provides a framework for guarding against ex-post transaction costs and performance problems by controlling the private objectives of partners at the cost of mutual benefits (Crocker \& Reynolds, 1993; Liu et al., 2017b). The more the extent to which a contract is complete, the less the ex-post transaction cost will be. However, previous empirical studies (Ruer \& Arino, 2002; Wuyts \& Geyskens, 2005; Woolthuis et al., 2005; Liu et al., 2009) have suggested that complete contracts, by clearly specifying the promises and obligations of each partner, enhance long-term commitment by mitigating opportunism. Based on 
the focus of our study, we thus argue that relationship partners may mitigate ex-post transaction costs and enhance relationship commitment by using more complete and detailed contractual design.

Symmetric dependence corroborates the idiosyncratic relationship-specific investments by both partners (Khalid \& Ali, 2017; Shen et al., 2017; Liu et al., 2017b) and enhance relationship commitment by creating interdependence between them. A high level of symmetrical interdependence is characterized by mutual investments indicating loyalty and cooperative longterm relationship (Caniëls \& Gelderman, 2007). Furthermore, it prohibits the market mechanism deployment and private control in the relationship and becomes critical for improving cost performance and learning (Chang \& Gotcher, 2007; Liu et al., 2017a). Previous seminal research has presented both positive and negative aspects of mutual investments in relation with transaction costs. For example, several researchers (e.g., Williamson, 1985; Dyer, 1997) argued that increase in asset specificity escalates opportunism, transaction costs and hold-up problems during the early stages of relationship. However, once the relationship is developed and adequate level of trust and symmetrical interdependence is attained, relationship partners become more loyal to each other (Liu et al., 2009) and expect continuous future transactions, thereby resulting in lower transaction costs. On the other hand, asymmetric interdependence can be counterproductive because less dependent partner dominates the relationship and exploits its weaker counterpart (Shen et al., 2017; Caniëls \& Gelderman, 2007) thereby resulting in lower commitment and higher transaction costs (Casciaro \& Piskorski, 2005). A fear of high switching costs enhances the relationship partners' interest in maintaining a quality relationship and commitment (Morgan \& Hunt, 1994). Following transaction cost reasoning, researchers argued that higher level of symmetric dependence displays strong and cooperative bond and provides incentives for not abandoning the exchange and for 
developing the relationship as successfully as possible (e.g., Caniëls \& Gelderman, 2007). Based on this theoretical examination, we argue that increase in the level of symmetric dependence creates mutual hostage and stabilizes the relationship by realigning the self-interest (Liu et al., 2017b), that influence ex-post transaction costs and serves as a structural rationale for long-term committed relationship. Hence, we hypothesize that

$\mathbf{H}_{\mathbf{1}}$ : There is a negative relationship between the use of economic governance mechanisms of (a) contract completeness and (b) symmetric dependence, and ex-post transaction costs.

$\mathbf{H}_{2}$ : There is a positive relationship between the use of economic governance mechanisms of (a) contract completeness and (b) symmetric dependence, and relationship commitment.

\subsection{Sociological governance mechanisms, transaction costs, and relationship commitment}

As sociological governance mechanism, trust is a significant factor for developing transaction cost performance, with the importance of a cooperative atmosphere having been emphasized in some empirical studies (e.g., Khalid \& Ali, 2017; Liu et al., 2017b). The willingness to trust or confidence in a partner, with regard to the other partner's reliability, benevolence, and integrity, significantly influence ex-post transaction costs and relationship commitment. The propensity of trust between relationship partners may determine their reliance on trust to minimize transaction costs (Brouthers \& Brouthers, 2003; Gulbrandsen et al., 2017). Ex-post transaction costs are minimized more effectively if a high level of inter-organizational trust is emplaced, as negotiations can be quickly and easily successful because of relationship partners' readiness (Zaheer et al., 1998). While low level of mutual trust enhances the complexities in a relationship, thereby resulting in higher transaction costs and lower commitment. Further, trusted partners spend less time in haggling over problems, adapting to unforeseen circumstances and spending fewer 
resources monitoring each other's behavior (Dyer \& Chu, 2011; Burkert et al., 2012). Williamson (1993a) argued that if the degree to which associated investments between relationship partners are not cost effective, calculative form of trust becomes the solution in order to economize transaction costs. Trust being multidimensional concept functions as a substitute for hierarchal control and minimizes both ex-ante and ex-post transaction costs by attenuating the efforts required to preempt the trustworthiness of counterpart. On the other hand, trust should positively impacts on relationship commitment. Trust is the main determinant of relationship commitment and firms seek only trustworthy relationship partners, therefore, the more the relationship partners trust each other, the more they feel committed and secured (Burkert et al., 2012). This narrative develops a perception of good faith, care and commitment for their counterpart rather than opportunistic behavior (Dyer \& Chu, 2003).

Communication as bilateral expectation of formal and informal information exchanges (Wang et al., 2016), can influence ex-post transaction costs and relationship commitment (Hung \& Lin, 2013). These bilateral expectations refer to the partners' beliefs regarding excellent communication, function as useful safeguards to deter conflicts, perceived risks and uncertainty (Heide \& John, 1992; Yen et al., 2011). Conversely, ineffective communication or asymmetric information sharing create misunderstanding and place the partner in jeopardy (Villena et al., 2011), which minimizes the likelihood of developing relationship quality and satisfaction (Hung \& Lin, 2013), and maximizes the time and effort required to negotiate (i.e. ex-post transaction costs). As communication promotes harmonization between relationship partners in terms of the timely available information, it also helps in fostering confidence in partner's reliability and integrity and thereby minimizes ex-post transaction costs (Hung \& Lin, 2013; Wang et al., 2016). Therefore, prior empirical research has found a negative impact of communication on relationship 
partners' bargaining costs (e.g., Yigitbasioglu, 2010). Furthermore, based on the loyalty and good faith between relationship partners, effective communication is crucial in knowledge sharing and cohesion, leading to conflict resolution and relationship commitment development (Yen et al., 2011; Hung \& Lin, 2013). Similarly, studies delineate that communication alleviates the uncertainty level and build a mutually bounded relationship thereby enhancing relationship commitment (e.g., Cai et al., 2009). Based on the above discussion, we derive the following hypotheses:

$\mathbf{H}_{3}$ : There is a negative relationship between the use of sociological governance mechanisms of (a) trust and (b) communication, and ex-post transaction costs.

$\mathbf{H}_{4}$ : There is a positive relationship between the use of sociological governance mechanisms of (a) trust and (b) communication, and relationship commitment.

\subsection{Interaction effects of economic and sociological governance mechanisms}

Prior research has presented two competing views toward the nature of the relationship, i.e. complementarity and substitution between relationship governance mechanisms. The complementarity view suggests that transactional and relational mechanisms function as complements (Luo, 2002; Poppo \& Zenger, 2002; Liu et al., 2009; Lee et al., 2017). However, the other view holds that, due to the varying nature of both transactional and relational mechanisms, joint adoption is less effective at governing inter-firm relationships (Wuyts \& Geyskens, 2005; Li et al., 2010). In this study, we examine how sociological governance mechanisms interact with contract completeness and symmetric dependence in minimizing ex-post transaction costs and maximizing relationship commitment. 


\subsubsection{Interaction of sociological governance mechanisms and contract completeness}

Seminal studies have viewed sociological governance mechanisms and contracts as substitutes believing that the presence of one prevents the use of other (Li et al., 2010; Lui \& Ngo, 2004; Wang et al., 2011). The theoretical reasons behind this substitution explain the importance of sociological governance against contractual safeguards. Indeed, a contract may minimize the risk of opportunism, it may also be seen as counterproductive to trust and bilateral communication (Dyer \& Singh, 1998). Further, researchers argued that sociological mechanisms mitigate relational risks by enhancing confidence in a partner's willingness (Lui \& Ngo, 2004), thereby minimizing the redundant specification of monitoring contractual clauses (Gulati \& Sytch, 2008; Li et al., 2010). This notion results in closer cooperation and fostered commitment between partners. On the other side, detailed contracts may be interpreted as a sign of unfairness and hinder the formation of sociological governance by enforcing contractual clauses (Lumineau \& Henderson, 2012), trust and communication, therefore undermine the negative influence of structural factors (Wang et al., 2011). Similarly, informal self-enforcing approaches relying on trust and communication undermine the use of formal governance of contracts (Dyer \& Singh, 1998). Contractual safeguards and controlling characteristics in the contract thus diminish the impact of sociological mechanisms, thereby restraining cooperative interactions between partners. Hawkins et al. (2008) argued that, over time, constant changes in strategies and extracted values may transform a relationship from being economic to social and vice versa. The underlying logic explains that drafting detailed and complex contracts may undermine the sociological governance, meaning that their combined use may not be effective. Therefore based on the above discussion and theoretical examination, this study argues that sociological governance mechanisms and 
contract completeness function as substitutes in minimizing ex-post transaction costs and fostering relationship commitment. Thus, the following hypothesis is proposed:

$\mathbf{H}_{5}$ : Sociological governance mechanisms and contract completeness will function as substitutes in (a) minimizing ex-post transaction costs, and (b) maximizing relationship commitment.

\subsubsection{Interaction of sociological governance mechanisms and symmetric dependence}

Despite the convincing opinions for viewing sociological governance and contract completeness as substitutes, the rationale for viewing sociological governance and symmetric dependence as complements seems equally compelling. The combination of sociological factors and symmetric dependence might provide greater inter-firm cooperation than employing them separately (Lee et al., 2017). Prior research has argued that symmetric dependence of inter-organizational exchange is socially embedded and complement in producing greater benefits (e.g., Dyer \& Chu, 2011; Granovetter, 2005; Liu et al., 2009). However, sociological mechanisms have limitations due to lack of explicit approaches and bounded rationality (Poppo \& Zenger, 2002), symmetric dependence therefore provides an institutional framework and complements sociological governance by offering structural constraints through a mutual hostage. Liu et al. (2009) argued that firms realize that damaging mutual specific investments can result in their reputation loss thus avoid opportunistic behavior when trust and effective communication are developed. Their significant empirical findings of complementarity interplay between economic and social factors are consistent with the prior seminal research (e.g., Poppo and Zenger, 2002). Thus, the underlying logic explains that symmetric dependence alone is insufficient in minimizing ex-post transaction costs and maximizing relationship commitment, because partners may not be able to resolve the conflicts and external uncertainty cooperatively. Additionally, sociological mechanisms alone can be insufficient because of the uncertainty regarding the fair reciprocal behavior of the counterpart 
(Ali \& Larimo, 2016). Where symmetric dependence promotes sociological governance, sociological factors facilitate structural framework to stabilize the relationship exchange. Therefore, we suggest positive reciprocal relationships between sociological governance mechanisms and symmetric dependence. Based on the above discussion, this study advances the following hypotheses:

$\mathbf{H}_{6}$ : Sociological governance mechanisms and symmetric dependence will function as complements in (a) minimizing ex-post transaction costs, and (b) maximizing relationship commitment.

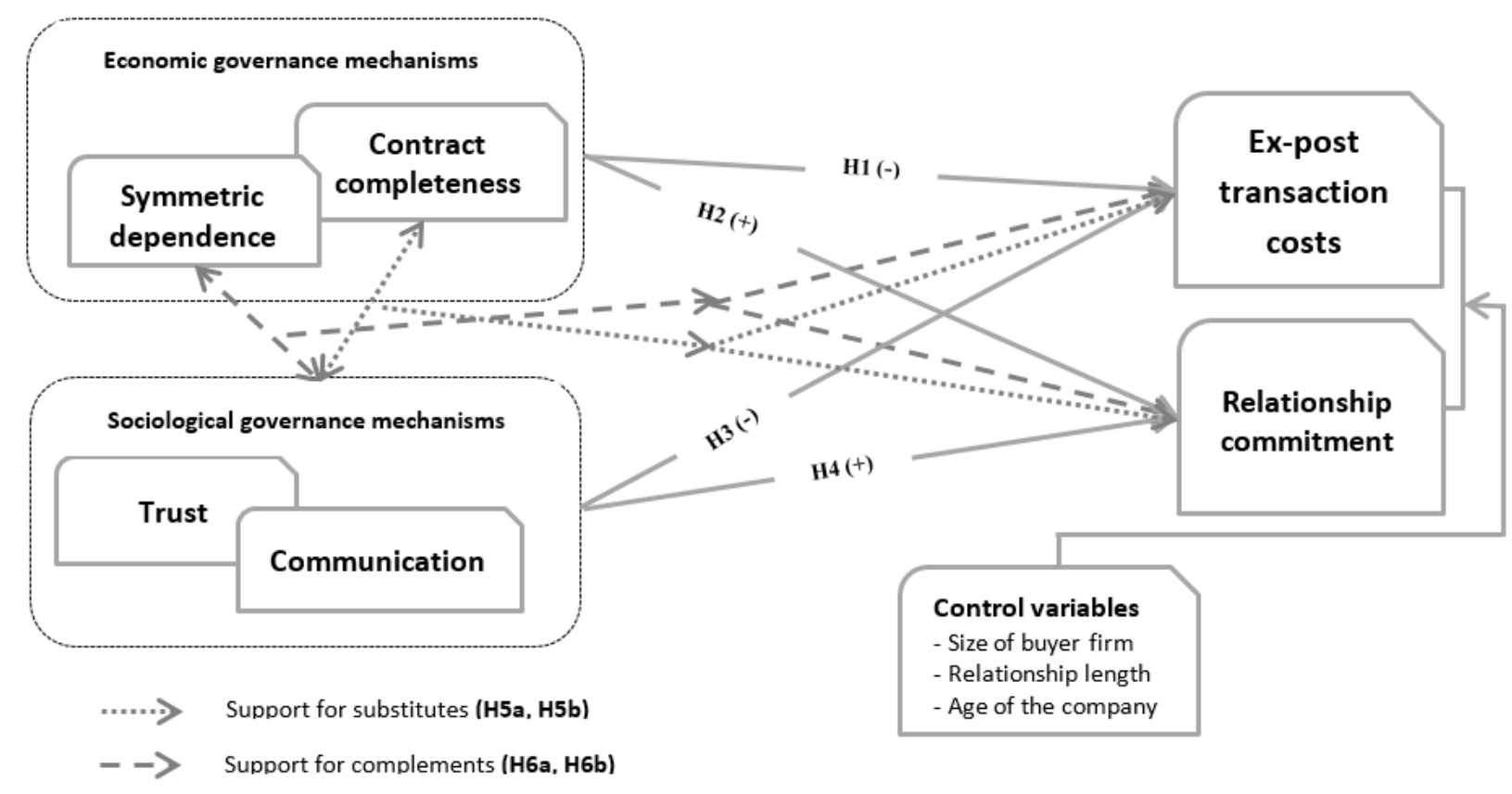

Figure 1 Conceptual model and hypotheses

\subsection{The relative importance of economic and sociological governance mechanisms}

As we have hypothesized the interplay between governance mechanisms in order to minimize expost transaction costs, we further predict that economic mechanisms are comparatively more effective than sociological mechanisms in improving cost performance (Yang et al., 2016). 
Relative effectiveness of governance mechanisms is characterized by nuanced understanding of contextual factors and boundary conditions. Different governance structures are required for different transaction objectives in governing relationship exchange. Better understanding of relationship outcomes and collaboration goals drive managers to analyze which governance mechanism is more crucial for a particular task (Yang et al., 2016; Liu et al., 2009). Based on TCE reasoning, employing more complete contract and symmetric dependence in a buyer-supplier relationship prevent the ex-post costs of enforcing and handling (Dyer \& Chu, 2003). Similarly, Poppo and Zenger (2002) manifested economic mechanisms as a formal framework to be used to resolve conflicts, alleviate the risk of misunderstandings, drive combined actions, and clarify the responsibilities and duties of each partner. Furthermore, explicitly described contractual clauses positively affect the use of a cooperative negotiation strategy (Lumineau \& Henderson, 2012) and facilitate the continuity of operations in effective manner (Yang et al., 2016), thereby reducing expost transaction costs. As, economic governance provide structural frameworks in curbing opportunism and transaction costs in a relationship exchange, sociological factors have limited power to discipline operations (Yang et al., 2016). Although trust clearly matters in relationship exchange and can significantly reduce transaction costs, relational governance settings alone do not completely provide formal framework and clear instructions in case of emergencies. Therefore, the risk of a partner's high level of trust, being exploited, becomes higher. Based on the abovementioned reasons and the structural logic behind the relative effectiveness of economic factors, we hypothesize that:

$\boldsymbol{H}_{7}$ : Economic governance mechanisms are more effective than sociological governance mechanisms at minimizing ex-post transaction costs. 
While we predicted that economic governance is more effective in minimizing ex-post transaction costs, sociological governance, on the other hand, can be more effective than economic factors at maximizing relationship commitment (Yang et al., 2016). Previous empirical studies argued that sociological governance mechanisms overcome the adaptive boundaries of complex contracts and function as informal instruments in developing relationship commitment (Krause et al., 2007; Kohtamäki et al., 2012). Therefore, this informal governance not only share the social platforms but also facilitate increased knowledge sharing, problem-solving efforts and learning within a relationship (Liu et al., 2009; Yang et al., 2016). Furthermore, relational instruments i.e. trust and communication function as a counterforce to power imbalance and minimizes the influence of power asymmetry, thereby enhancing commitment and desire to continue the long-term relationship (Yang et al., 2016). Commitment flourishes and develops more when factors, such as trust, norms of flexibility, solidarity, and communication, robustly exist in a relationship (Poppo \& Zenger, 2002). On the contrary, because economic governance create an explicit structural system, in which both parties must comply, the motivation to enhance relationship commitment is thus constrained. Sociological governance, therefore, support flexible environment and encourage relationship partners to engage in such activities beyond the limits of interdependence and contract clauses in order to enhance relationship commitment (Liu et al., 2009; Yang et al., 2016). Based on the above-mentioned reasons and the social logic behind the relative effectiveness of sociological governance factors, we hypothesize the following:

$\boldsymbol{H}_{8}:$ Sociological governance mechanisms are more effective than economic governance mechanisms at maximizing relationship commitment. 


\section{Research methodology}

\subsection{Data collection}

This study consists of Finnish SMEs involved in buyer-supplier relationships operating with key suppliers (i.e. suppliers providing key components and services) from a variety of countries in Asia and Europe, as well as the USA. A sample of 892 potential SMEs was generated from a database operated by the Collector Finland (i.e., a financial service provider, offering cost-effective and innovative solutions to private and corporate customers in Nordic countries), which includes basic information about Nordic buyer-supplier relationships. The sample indicates that 170 SMEs had suppliers in three regions (Europe: 143; USA: 17; Asia: 10), with an average size of 24 employees/SME and an average turnover of $€ 38 \mathrm{~m} / \mathrm{SME}$. The SMEs in the data set were operating in several dispersed classified industries, with $66.47 \%$ belonging to manufacturing and $33.53 \%$ belonging to the services industry. However, it was less useful when attempting to identify economic and sociological governance factors pertaining to the management of buyer-supplier relationships from the database. Therefore, we decided to collect primary data from key executives from Finnish SMEs in order to obtain the essential details on these buyer-supplier relationship issues. This database was used to identify the names and emails of potential respondents, while most of them were CEOs, CFOs, and board directors. Pre-testing was executed among the research group members in order to determine whether the respondents apprehend the questions as offered. Thus in spring 2015, a web-based questionnaire was designed (Dillman et al., 2009) and sent to 892 firms by following another email to non-respondents three weeks later. In result, we collected 170 usable responses, yielding a response rate of 19.06\% (170 of 892).

Despite this response rate, we performed an independent sample t-test as proposed by Armstrong and Overton (1977) in order to measure whether, and to what extent, this survey was subject to 
non-response bias, and to analyze the difference between early and late respondents $(\mathrm{N}=85 ; \mathrm{N}=$ 85). No significant differences between the early and late respondents were found in terms of firm's size $(\mathrm{p}=.510)$ and length of the relationship $(\mathrm{p}=.319)$. Therefore, non-response bias was not a problem for this study. Prior methodological literature, as well as many empirical studies (e.g., Ali \& Larimo, 2016; Silva et al., 2012), have taken the stance that late respondents are also representative of non-respondents.

A likelihood of common method variance exists in the research when all the constructs are measured using the same survey (Podsakoff et al., 2003; Najafi-Tavani et al., 2015). Therefore, in order to measure and control for potential effect of common method bias, ex-ante and ex-post strategies were followed (Chang et al., 2010). During the ex-ante research design stage, we followed different strategies. First, respondents were guaranteed of anonymity and confidentiality regarding the study. Second, the sequence of questions was emplaced in a way that a logical relationship between the variables seemed unapparent, as questions related to ex-post transaction costs and relationship commitment were asked in different sections. After we collected data, we performed Harman's one-factor test as an ex-post approach in order to measure the degree to which collected data is influenced negatively by common method bias. In result of non-rotated factor solution in exploratory factor analysis, no single or general factor was apparent explaining most of the variability in the data, with major factor accounting for $26.88 \%$ of total variance. Thus, common method variance was not a problem in the analysis.

\subsection{Measures}

This study employs reflective measurement models and the items used to operationalize each construct were developed on a 7-point Likert scale based on the existing literature. All the 
constructs demonstrated satisfactory reliability and validity with their Cronbach's Alpha (CA), Average Variance Extracted (AVE) and Composite Reliability (CR) values as well as item loadings in Table 1. We adapted four items for the ex-post transaction costs construct from Zaheer et al. (1998), which demonstrated satisfactory reliability and validity (AVE: .79; CA: .75; CR: .83). Relationship commitment was measured using four items (AVE: .80; CA: .79; CR: .92) based on Anderson and Weitz (1992) and Tellefsen (2002). Trust was measured by adapting seven items (AVE: .78; CA: .81; CR .93) from Morgan and Hunt (1994). Communication was operationalized adapting four items (AVE: .83; CA: .93; CR.95) drawing from Heide and John (1992) and YoungYbarra and Wiersema (1999). Contract completeness including term specificity and contingency adaptability was measured using six items (AVE: .77; CA: .93; CR .95), based on Luo (2002, 2009).

The method that we employed to measure the level of symmetric dependence between partners was adapted from previous empirical studies (e.g., Ali \& Larimo, 2016; Khalid \& Ali, 2017). Symmetric dependence characterizes the extent to which both buyer and supplier are interdependent and have invested equal idiosyncratic specific assets ranged from " 1 = very low to 7 = very high". Therefore, it was divided into buyer's dependence and supplier's dependence. Buyer dependence comprises of two items, adapted from previous research: A- we need the size of investment in a focal relationship, and B- we need the level of replicability, that is, we need to measure difficulty in redeploying the resources outside the relationship (e.g. Zeng, 1998; Reuer \& Arino, 2002; Young-Ybarra \& Wiersema, 1999). In order to determine the dependence of buyer firm, these two items were collapsed into one. Similarly, respondents were also asked the same questions to specify the size of supplier's investments in the relationship and the difficulty level of supplier's investment redeployment, that were collapsed into one in order to calculate supplier 
dependence. To determine the level of symmetric dependence between buyer and supplier, a calculation was made by taking the absolute difference between both partner's interdependence. In this instance, a zero specified a perfectly symmetric dependence of both parties. This measure explains the perfect symmetric dependence between partners in case of both high mutual dependence and low mutual dependence.

To exemplify, suppose we have a case wherein (A) the size of investment is 4 out of 7; and (B) the difficulty to replace is 5 out of 7 . In this case, we calculate the level of dependence by multiplying A by B; that is the buyer's dependence is $4 * 5=20$. Similarly, if the calculation of supplier's dependence is also 20, we have a pair of buyer and supplier in which both have similar level of dependence, i.e. 20. As such, the difference between these values is $20-20=0$, representing a perfect symmetric dependence. These calculations helped us to determine the level of symmetrical interdependence between buyer and supplier in order to analyze the data. Three additional variables of less interest were included to control the dependent variables. These include age of the firm, relationship length (Liu et al., 2009), and size of the buyer firm (Luo et al., 2015) as control variables because of their potential effect on dependent variables. Age of the firm was measured as the number of years in operation and size of the firm as a number of employees. Finally, relationship length indicates the time period of the relationship between buyer and supplier.

Table 1. Constructs, item loadings, Cronbach's alpha (CA), AVE and composite reliability values (CR)

\begin{tabular}{lcc}
\hline Constructs and items & Loadings & Item source(s) \\
\hline Ex-post transaction cost (AVE: .79; CA: .75; CR: .83) & Zaheer et al. (1998) \\
How easy are negotiations between your firm and key supplier firm over sharing the burden of costs & \\
(not explicitly covered by the contract) when (very difficult 1-7 very easy): & 0.85 \\
...your business unit requests engineering changes? & 0.87 \\
...supplier X's raw material costs increase? & & \\
How quick are negotiations between your firm and key supplier firm over sharing the burden of & \\
costs (not explicitly covered by the contract) when (very slow 1-7 very quick): & 0.81 \\
...your business unit requests engineering changes? & 0.83 & Anderson and Weitz (1992) \\
...supplier X's raw material costs increase? & & and Tellefsen (2002)
\end{tabular}


Please indicate how strongly you agree with the following statements concerning supplier commitment (strongly disagree $1-7$ strongly agree)?

...we have a strong sense of loyalty to our key supplier

...we are continually on the lookout for new sources to replace our supplier (R)

...we are very committed to our key supplier

...we expect to be doing business with our key supplier for a long time

Trust (AVE: .78; CA: .81; CR .93)

Please indicate your level of agreement with the following statements (strongly disagree 1-7 strongly agree):

Our key supplier firm:

...cannot be trusted at times $(\mathrm{R})$

...is perfectly honest and truthful

...can be trusted completely

...can be counted on to do what is right

...is always faithful

...is someone I have great confidence in

...has high integrity

Communication (AVE: .83; CA: .93; CR .95)

Regarding communication between you and your key supplier, please indicate your level of agreement with the following statements (strongly disagree 1-7 strongly agree):

...we always keep each other informed about events or changes that may affect the other party

...it is expected that any information, which might help the other party, will be provided to them

...it is expected that proprietary information will be shared if it can help the other party

...exchange of information in this relationship takes place frequently and informally, not only according to a pre-specified agreement

Contract completeness (AVE: .77; CA: .93; CR .95)

To what extent are the following arrangements with your key supplier firm formalized in the written contract (not at all 1-7 entirely)?

...how to operate and manage the relationship

...how to cooperate, coordinate, and resolve conflicts between your firm and key supplier

...how to terminate the relationship

...how to handle the unanticipated contingencies during relationship formation and operation

...cost and quality of resources invested in relationship

...how to secure invested resources from exploitation

Symmetric dependence

Items measuring the dependence of buyer firm (very low 1-7 very high)

...our investment in the relationship is

....if this relationship was to dissolve, our non-recoverable investments would be

Items measuring the dependence of key supplier firm (very low 1-7 very high):

...supplier firm's investment in the relationship is

...if this relationship was to dissolve, the key supplier firm's non-recoverable investments would be Symmetric dependence:

Level of symmetric dependence between buyer and key supplier (i.e., difference between dependence of buyer and supplier firm) $[0=7,1-8=6,9-16=5,17-24=4,25-32=3,33-40=2,41-48=1]$
Heide and John (1992) and Young-Ybarra and Wiersema (1999)

\subsection{Measure validation}

To analyze our deductive-nomological model, we utilized a nonparametric technique (i.e., partial least squares - PLS) to variance-based structural equation modeling (SEM) by using SmartPLS 2.0 software (Chin, 1998; Ringle, Wende \& Will, 2005) for the following reasons. Firstly, we adopted variance based PLS-SEM approach because this study tests an explorative model with alternative hypotheses, i.e. whether economic and sociological governance mechanisms (direct effect and interaction effect) explain ex-post transaction costs and relationship commitment. Secondly, PLS- 
SEM is capable of modeling latent constructs beyond measurement error, therefore is appropriate to test interaction effects in particular (Chin, 1998; Mitchell et al., 2008). Thirdly, PLS-SEM modelling is not only considered as the most suitable approach when dealing with a small sample size but it also allows researchers to evaluate both formative and reflective measurement models simultaneously as well as hierarchical models (Becker et al., 2012; Hair et al., 2012a). Thus, it exhibits higher statistical power than covariance-based SEM when used on complex models with limited sample size (Hair et al., 2012a; Hair et al., 2012b; Chin, 1998). This is particularly applicable to this study, as the final sample size was 170 buyer-supplier relationships. Furthermore, multivariate normal data is not required in PLS-SEM modeling (Chin, 1998). Therefore, growing number of recent industrial marketing and management studies employed PLS-SEM because of its dynamic attributes (e.g., Kohtamäki et al., 2012; Khalid \& Ali, 2017; Zaefarian et al., 2017; Najafi-Tavani et al., 2015; Mitrega et al., 2017).

Although PLS modeling evaluates both structural and measurement model at the same time, this study followed Hulland's (1999) technique in testing models. We analyzed and interpreted the estimated model in two phases: first, the estimation and reliability of the measurement model, and, second, the evaluating the structural model. We also validated measurement model by evaluating the individual item reliabilities: convergent and discriminant validity (Chin, 1998; Hair et al., 2012b). All the loaded indicators on latent variables are above Gotz et al.'s (2010) recommended a level of 0.7 , which specifies a high degree of item reliability, whereas the mean of composite reliability (CR) represents the construct reliability for each latent variable. The composite reliability is noted higher than the threshold of 0.6. Further, the average variance extracted (AVE) with a greater value than the threshold of 0.5 is considered for all the latent variables in order to 
evaluate the convergent validity of the reflective block of the model (Gotz et al., 2010), demonstrating satisfactorily valid.

Table 2 exhibits the inter-construct correlations and average variance extracted. Previous studies also recommended that if square roots of the AVEs are statistically higher than correlations among the latent constructs, discriminant validity could be assured (Chin, 1998; Gotz et al., 2010). We also assessed the level of multi-collinearity between the constructs and variance inflation factor (VIF) was found well below five (the highest VIF values is 1.78), thus indicating no significant multi-collinearity (Hair et al., 2012a, 2012b). Additionally, we computed a confirmatory factor analysis, and the results specify a good model fit $\left(\chi^{2}=277.90\right.$, d.f. $=165$, RMSEA $=.064$, GFI $=$ $.873, \mathrm{CFI}=.961, \mathrm{NFI}=.911, \mathrm{IFI}=.962)$. Hence, we safely conclude that all the constructs and items were found to be satisfactorily sound, assuring discriminant validity and reliability.

\section{Analysis and results}

\subsection{Structural estimates}

We employed PLS-analysis (a path weighting technique with a maximum of 300 iterations) in order to test our direct effect and interaction effect hypotheses (i.e. $\mathrm{H}_{1}-\mathrm{H}_{6}$ ), and a bootstrapping method of sampling was utilized to generate t-values (Hair et al., 2012a; Chin, 1998). These structural estimations are presented in table 3 where $\mathrm{R}^{2}$ (i.e., the coefficient of determination) for the dependent variable, path loadings (i.e., standardized $\beta$ ) and significance levels demonstrate the main effects (Gotz et al., 2010). The nomological validity of our model was evaluated by examining the explained variance $\mathrm{R}^{2}$ for each dependent construct in our framework (Sarstedt et al., 2014). The $\mathrm{R}^{2}$ for dependent variables in Models 3 and 7 are 0.29 and 0.32 , respectively, which posits that the independent constructs describe $29 \%$ of the variance in ex-post transaction costs and $32 \%$ of the variance in relationship commitment. 
Table 2. Inter-construct correlations, AVE and square roots of AVE along the diagonal

\begin{tabular}{lcccccccccc}
\hline \multicolumn{1}{c}{ Constructs } & AVE & $\mathbf{1}$ & $\mathbf{2}$ & $\mathbf{3}$ & $\mathbf{4}$ & $\mathbf{5}$ & $\mathbf{6}$ & $\mathbf{7}$ & $\mathbf{8}$ & $\mathbf{9}$ \\
\hline 1. Communication & 0.83 & 0.91 & & & & & & & & \\
2. Trust & 0.78 & 0.47 & 0.88 & & & & & & & \\
3. Contract completeness & 0.77 & 0.20 & 0.12 & 0.88 & & & & & & \\
4. Symmetric dependence & 1 & 0.04 & 0.02 & 0.04 & 1 & & & & & \\
5. Age of the company & 1 & 0.19 & -0.01 & 0.06 & 0.06 & 1 & & & & \\
6. Relationship length & 1 & 0.23 & 0.04 & 0.08 & 0.07 & 0.52 & 1 & & & \\
7. Size of buyer firm & 1 & 0.02 & -0.06 & 0.08 & -0.07 & 0.32 & 0.28 & 1 & & \\
8. Transaction costs & 0.79 & -0.31 & -0.17 & -0.29 & -0.12 & -0.04 & -0.12 & 0.04 & 0.89 & \\
9. Relationship commitment & 0.80 & 0.47 & 0.36 & 0.28 & 0.10 & 0.09 & 0.16 & 0.00 & -0.35 & 0.89 \\
\hline
\end{tabular}

From the results of Model 3, significant negative relationships were found between contract completeness and ex-post transaction costs $(\beta=-0.40, \mathrm{p} \leq 0.01)$ and between symmetric dependence and ex-post transaction costs $(\beta=-0.13, \mathrm{p} \leq 0.05)$. These results support $\mathrm{H}_{1}$. Further, Model 7 shows that contract completeness $(\beta=0.19, \mathrm{p} \leq 0.01)$ exerts a significant and positive effect on relationship commitment. However, symmetric dependence does not significantly relate to relationship commitment. These results partially support $\mathrm{H}_{2}\left(\mathrm{H}_{2} \mathrm{a}=\right.$ supported, $\mathrm{H}_{2} \mathrm{~b}=$ not supported) ${ }^{1}$. Furthermore, from Model 3, significant negative relationships were found between communication and ex-post transaction $\operatorname{costs}(\beta=-0.30, \mathrm{p} \leq 0.05)$ and between trust and ex-post transaction costs $(\beta=-0.18, \mathrm{p} \leq 0.05)$. These results support $\mathrm{H}_{3}$. Further results from Model 7 indicate that communication $(\beta=0.33, \mathrm{p} \leq 0.01)$ and trust $(\beta=0.17, \mathrm{p} \leq 0.05)$ exert a significant and positive effect on relationship commitment. These results support $\mathrm{H}_{4}$.

Table 3. PLS analysis results (standardized beta coefficients \& t-values)

\begin{tabular}{|c|c|c|c|c|c|c|c|c|}
\hline \multirow[t]{2}{*}{ Constructs } & \multicolumn{4}{|c|}{ Transaction costs } & \multicolumn{4}{|c|}{ Relationship commitment } \\
\hline & Model 1 & $\begin{array}{l}\text { Model } \\
2\end{array}$ & Model 3 & Model 4 & Model 5 & Model 6 & Model 7 & Model 8 \\
\hline $\begin{array}{l}\text { Contract } \\
\text { completeness }\end{array}$ & $\begin{array}{l}-0.28 \\
(2.93)^{* * *}\end{array}$ & & $\begin{array}{l}-0.40 \\
(2.51)^{* *}\end{array}$ & $\begin{array}{l}-0.24 \\
(2.36)^{* *}\end{array}$ & $\begin{array}{l}0.28 \\
(2.68) * *\end{array}$ & & $\begin{array}{l}0.19 \\
(2.27)^{* *}\end{array}$ & $\begin{array}{l}0.27 \\
(2.40)^{* *}\end{array}$ \\
\hline
\end{tabular}

\footnotetext{
${ }^{1}$ We further split the contract completeness construct into two sub-dimensions of term specificity and contingency adaptability and examined the effect of each of these sub-dimensions on both ex-post transaction costs as well as on relationship commitment. The results suggests that term specificity has negative impact on ex-post transaction costs $(\beta=-0.28, \mathrm{p} \leq 0.05)$ and positive impact on relationship commitment $(\beta=0.27, \mathrm{p} \leq 0.05)$, however the path from contingency adaptability to these dependent variables while in a right direction, is not significant. These finding suggest that term specificity is more important in explaining transaction cost and can increase relationship commitment.
} 


\begin{tabular}{|c|c|c|c|c|c|c|c|c|}
\hline $\begin{array}{l}\text { Symmetric } \\
\text { dependence }\end{array}$ & $\begin{array}{l}-0.16 \\
(1.82)^{*}\end{array}$ & & $\begin{array}{l}-0.13 \\
(1.73)^{*}\end{array}$ & $\begin{array}{l}-0.12 \\
(1.69)^{*}\end{array}$ & $0.11(1.42)$ & & $0.09(1.31)$ & $0.07(1.12)$ \\
\hline Communication & & $\begin{array}{l}-0.31 \\
(2.02)^{*}\end{array}$ & $\begin{array}{l}-0.30 \\
(1.67)^{*}\end{array}$ & $\begin{array}{l}-0.22 \\
(1.78)^{*}\end{array}$ & & $\begin{array}{l}0.37 \\
(3.08)^{* * *}\end{array}$ & $\begin{array}{l}0.33 \\
(2.83)^{* *}\end{array}$ & $\begin{array}{l}0.30 \\
(2.69)^{* *}\end{array}$ \\
\hline Trust & & $\begin{array}{l}-0.19 \\
(1.85)^{*}\end{array}$ & $\begin{array}{l}-0.18 \\
(1.73)^{*}\end{array}$ & $\begin{array}{l}-0.16 \\
(1.66)^{*}\end{array}$ & & $\begin{array}{l}0.18 \\
(1.69)^{*}\end{array}$ & $\begin{array}{l}0.17 \\
(1.70)^{*}\end{array}$ & $\begin{array}{l}0.16 \\
(1.67)^{*}\end{array}$ \\
\hline $\begin{array}{l}\text { Interaction effects } \\
\text { Trust* contract } \\
\text { completeness }\end{array}$ & & & & $\begin{array}{l}0.19 \\
(1.91)^{*}\end{array}$ & & & & $\begin{array}{l}-0.16 \\
(1.83)^{*}\end{array}$ \\
\hline $\begin{array}{l}\text { Communication* } \\
\text { contract completeness }\end{array}$ & & & & $0.06(0.34)$ & & & & $\begin{array}{l}-0.20 \\
(1.84)^{*}\end{array}$ \\
\hline $\begin{array}{l}\text { Trust* symmetric } \\
\text { dependence }\end{array}$ & & & & $\begin{array}{l}-0.17 \\
(1.81)^{*}\end{array}$ & & & & $\begin{array}{l}0.14 \\
(1.76)^{*}\end{array}$ \\
\hline $\begin{array}{l}\text { Communication* } \\
\text { symmetric } \\
\text { dependence }\end{array}$ & & & & $\begin{array}{l}-0.15 \\
(1.69)^{*}\end{array}$ & & & & $\begin{array}{l}0.13 \\
(1.66)^{*}\end{array}$ \\
\hline \multicolumn{9}{|l|}{ Control variables } \\
\hline $\begin{array}{l}\text { Size of buyer firm } \\
\text { (i.e., \# of employees) }\end{array}$ & $0.09(0.82)$ & $\begin{array}{l}0.05 \\
(0.46)\end{array}$ & $0.02(0.65)$ & $0.03(0.28)$ & $\begin{array}{l}-0.06 \\
(0.64)\end{array}$ & $-0.01(0.19)$ & $\begin{array}{l}-0.02 \\
(0.30)\end{array}$ & $0.01(0.08)$ \\
\hline Length of relationship & $-0.15(1.13)$ & $\begin{array}{l}-0.10 \\
(0.75)\end{array}$ & $\begin{array}{l}-0.02 \\
(0.79)\end{array}$ & $\begin{array}{l}-0.10 \\
(0.80)\end{array}$ & $0.16(1.33)$ & $0.09(0.74)$ & $0.08(0.68)$ & $0.06(0.60)$ \\
\hline Age of company & $0.04(0.26)$ & $\begin{array}{l}0.05 \\
(0.34)\end{array}$ & $0.01(0.47)$ & $0.10(0.82)$ & $\begin{array}{l}-0.01 \\
(0.02)\end{array}$ & $-0.02(0.21)$ & $\begin{array}{l}-0.02 \\
(0.21)\end{array}$ & $\begin{array}{l}-0.01 \\
(0.13)\end{array}$ \\
\hline $\mathrm{R}^{2}$ & 0.25 & 0.21 & 0.29 & 0.35 & 0.19 & 0.25 & 0.32 & 0.43 \\
\hline
\end{tabular}

Models 4 and 8 respectively in Table 3 are used to examine the interaction effects between sociological mechanisms and contract completeness and between sociological mechanisms and symmetric dependence in relation to ex-post transaction costs and relationship commitment. We mean-centered and multiplied the indicators of sociological mechanisms and economic factors to obtain the interaction effects. Several researchers have confirmed that negative coefficients of interacting variables would support a substitute relationship whereas positive coefficients suggest a complementary relationship (e.g., Poppo \& Zenger, 2002; Liu et al., 2009; Li et al., 2010; Wang et al., 2011). In relation to ex-post transaction costs, results in Model 4 suggest that interaction between trust and contract completeness $(\beta=0.19, \mathrm{p} \leq 0.05)$ is positive and significant while the interaction between communication and contract completeness is positive, albeit non-significant. Whereas, the results from Model 8 show that interaction between trust and contract completeness 
$(\beta=-0.16, \mathrm{p} \leq 0.05)$, is negative and significant. Similarly, the interaction between communication and contract completeness $(\beta=-0.20, \mathrm{p} \leq 0.05)$ is negative and significant, in relation to relationship commitment. These results partially support $\mathrm{H}_{5}$ a and completely support $\mathrm{H}_{5} \mathrm{~b}$, representing substitute relationships between sociological governance mechanisms and contract completeness. Further, in relation to ex-post transaction costs, the interaction between trust and symmetric dependence $(\beta=-0.17, \mathrm{p} \leq 0.05)$ is negative and significant. Meanwhile, the interaction between communication and symmetric dependence is negative and significant $(\beta=-0.15, \mathrm{p} \leq$ $0.05)$. On the other hand, the interaction between trust and symmetric dependence $(\beta=0.14, \mathrm{p} \leq$ 0.05), in relation to relationship commitment, is significant and positive, while the interaction between communication and symmetric dependence $(\beta=0.13, \mathrm{p} \leq 0.05)$ is significant and positive. These results lend full support to $\mathrm{H}_{6} \mathrm{a}$ and $\mathrm{H}_{6} \mathrm{~b}$, representing complementary relationships between sociological governance mechanisms and symmetric dependence.

\subsection{Relative power of governance mechanisms}

To test hypotheses $\mathrm{H}_{7}$ and $\mathrm{H}_{8}$, two methods were employed to compare the relative powers of economic and sociological governance mechanisms, as offered and used by Liu et al. (2009). Firstly, if we take "ex-post transaction costs", for example, we can get $\Delta \mathrm{R}^{2}$ as per the regression results of Models 1, 2 and 3:

$$
\begin{aligned}
\Delta \mathrm{R}^{2} \text { Model 3-Model 1 } & =\mathrm{R}^{2}{ }_{\text {Model 3- }} \mathrm{R}^{2} \text { Model 1 }=.29-.25 \\
& =.04 \\
\Delta \mathrm{R}^{2} \text { Model 3-Model 2 } & =\mathrm{R}^{2}{ }_{\text {Model 3 }}-\mathrm{R}^{2}{ }_{\text {Model } 2}=.29-.21 \\
& =.08
\end{aligned}
$$

Here, $\Delta \mathrm{R}^{2}$ Model 3-Model 1 describes the proportion of the variance of ex-post transaction costs that sociological mechanisms can explain, while $\Delta \mathrm{R}^{2}$ Model 3-Model 2 represents the proportion of the 
variance of ex-post transaction costs, that economic mechanisms can explain. As $\Delta \mathrm{R}^{2}$ Model 3 -Model ${ }_{2}>\Delta \mathrm{R}^{2}$ Model 3-Model 1, this suggests that economic mechanisms are statistically stronger in effecting ex-post transaction costs than sociological mechanisms. Further, taking "relationship commitment" as the dependent variable, we acquire $\Delta \mathrm{R}^{2}$ as per the regression results of Models 5 , 6 and 7:

$$
\begin{aligned}
\Delta \mathrm{R}^{2} \text { Model 7-Model 5 } & =\mathrm{R}^{2} \text { Model } 7-\mathrm{R}^{2} \text { Model } 5=.32-.19 \\
& =.13 \\
\Delta \mathrm{R}^{2} \text { Model 7-Model 6 } & =\mathrm{R}^{2} \text { Model } 7-\mathrm{R}^{2} \text { Model 6 }=.32-.25 \\
& =.07
\end{aligned}
$$

Here, $\Delta \mathrm{R}^{2}$ Model 7-Model 5 represents the proportion of the variance of relationship commitment, that sociological mechanisms can explain, while $\Delta \mathrm{R}^{2}$ Model 7-Model 6 represents the proportion of the variance of relationship commitment, that economic mechanisms can explain. As $\Delta \mathrm{R}^{2}$ Model 7 -Model ${ }_{6}<\Delta \mathrm{R}^{2}$ Model 7-Model 5, this suggests that sociological mechanisms are statistically stronger in influencing relationship commitment than economic mechanisms. Notably, none of the control variables was significantly related to ex-post transaction costs and relationship commitment.

Secondly, the semi-partial correlation was performed to further examine the above relative predicting power (see Table 4), which represents the independent influence of a predicting variable to the dependent variable controlling for the effect of other variables (Liu et al., 2009). The impact of economic mechanisms on attenuating ex-post transaction costs equals the sum of the impact of contract completeness and symmetric dependence, which is $0.081(0.060+0.021)$. Similarly, the impact of sociological mechanisms on shrinking ex-post transaction costs equals to the sum of the impact of trust and communication, which is $0.055(0.030+0.025)$. The impact of economic mechanisms on ex-post transaction costs is found to be stronger than the impact of sociological 
mechanisms. This test also confirms that the impact of economic mechanisms on relationship commitment $(0.029+0.001=0.030)$ is smaller than that of sociological mechanisms $(0.076+$ $0.022=0.098)$. Therefore, these findings support $\mathrm{H}_{7}$ and $\mathrm{H}_{8}$, which recommend that economic governance mechanisms are more powerful in shaping ex-post transaction costs, while sociological governance mechanisms are more effective in maximizing relationship commitment.

Table 4. Semi-partial correlation for the predicting power of governance mechanisms

\begin{tabular}{|c|c|c|c|c|}
\hline & \multicolumn{2}{|c|}{ Ex-post transaction costs } & \multicolumn{2}{|c|}{ Relationship commitment } \\
\hline & Part correlation & Square of part correlation & Part correlation & $\begin{array}{l}\text { Square of part } \\
\text { correlation }\end{array}$ \\
\hline \multicolumn{5}{|c|}{ Economic governance mechanisms } \\
\hline Contract completeness & -0.246 & 0.060 & 0.170 & 0.029 \\
\hline Symmetric dependence & -0.147 & 0.021 & 0.039 & 0.001 \\
\hline \multicolumn{5}{|c|}{ Sociological governance mechanisms } \\
\hline Communication & -0.176 & 0.030 & 0.275 & 0.076 \\
\hline Trust & -0.159 & 0.025 & 0.150 & 0.022 \\
\hline \multicolumn{5}{|l|}{ Control variables } \\
\hline \# of employees & 0.052 & 0.002 & -0.108 & 0.012 \\
\hline Age of company & 0.068 & 0.005 & 0.011 & 0.000 \\
\hline Age of relationship & -0.090 & 0.008 & 0.071 & 0.005 \\
\hline
\end{tabular}

\section{Discussion and implications}

\subsection{Results summary}

We developed and empirically tested a combined model of economic (i.e., contract completeness and symmetric dependence) and sociological (i.e., trust and communication) governance mechanisms, which minimize ex-post transaction costs and maximize relationship commitment. Based on the analysis of 170 buyer-supplier relationships involving Finnish SMEs, this study had resulted in several noteworthy findings. First, economic and sociological mechanisms are equally important in terms of transaction costs containment to relationship commitment development. Second, this study notably incorporates complementarity view of sociological governance mechanisms and symmetric dependence, consistent with prior research. On the other hand, sociological governance mechanisms and contractual governance found as substitutes in 
explaining ex-post transaction costs and relationship commitment. Third, economic mechanisms perform a more powerful role in minimizing ex-post transaction costs, whereas sociological mechanisms enhance relationship commitment more effectively. Overall, these results suggest the significance of varying roles of relationship governance mechanisms in order to govern relationship exchange effectively.

\subsection{Theoretical implications}

Recent studies have emphasized on governance structure that develops relationship performance (Liu et al., 2017a; Luo et al., 2015), credibility and quantity of knowledge transfer (Liu et al., 2017b), relational satisfaction (Yang et al., 2016; Gorton et al., 2015) while minimizing conflicts (Lee et al., 2017; Yang et al., 2017) and opportunism (Luo et al., 2015; Liu et al., 2009). Conflicting empirical results on the nature of governance mechanisms (i.e., commentary and/or substitutes) and their isolated existence have overlooked the significant question of varying roles of governance mechanisms. Therefore, this study contributes to the industrial marketing and management literature by providing a comprehensive picture of relative effectiveness, as well as the joint use of both economic and sociological governance structure.

In particular, we advance the research in following ways. First, this study develops an integrated framework of inter-organizational cooperation by synthesizing two relevant theories, namely, TCE and SET. The findings support and add to TCE reasoning and empirically demonstrate that the higher extent of contract completeness prevents the possibilities of exchange hazards, conflicts and contingencies, and opportunistic behavior (Luo, 2009; Liu et al., 2009; Liu et al., 2017b). Our findings offer an additional insight by providing empirical evidence in an SME setting and explain that contractual governance provides an institutional framework to relationship partners in 
safeguarding ex-post transaction costs, opportunistic behavior and performance problems by controlling the private objectives of partners at the cost of mutual benefits (Lee et al., 2017). Furthermore, the significant effect of symmetric dependence in terms of minimizing ex-post transaction costs reveals that increase in the level of symmetric dependence creates mutual hostage and loyalty, and stabilizes the relationship by realigning the self-interest and the expectations of continuous future transactions (Liu et al., 2009; Liu et al., 2017b). Similarly, a relatively complete contract keeps the relationship partners committed by providing a convincing signal, restraining uncertainty about behaviors and functioning as deterrence against exploitation and opportunism. Thus, contractual completeness is considered as important manifestation of tangible expressions of confidence and commitment between relationship partners by explicitly clarifying prior equivocal results (Woolthuis et al., 2005; Burkert et al., 2012).

However, contrary to the expectation, we found no significant positive relationship between symmetric dependence and relationship commitment. This finding is against the arguments advanced by scholars (e.g., Xie et al., 2010; Burkert et al., 2012) who posit that idiosyncratic relationship-specific investment are considered as a commitment device as well as the indications of adopting longstanding coordination by contributing a strong bond and providing incentives for not abandoning the exchange relationship. One possible explanation for this may be that symmetric dependence includes not only the issue of symmetry but also the level of mutual dependence (i.e., high and low mutual dependence) since low and high mutual dependence should not have the same impact on relationship commitment. It is not likely that firms are more committed at a lower level of symmetric dependence because of their lower stakes in the relationship. Furthermore, the level of interdependence between firms may vary because same amount of relationship-specific 
investments do not mean the same to the firms highly different in size (i.e., an investment of 1 million US\$ does not mean the same to each partner).

Among the sociological governance mechanisms, our findings also confirm some major reasoning found in the literature and demonstrate the effectiveness of trust and communication. SET suggests that relationship exchange should be rooted in strong relational ties between buyer and supplier in order to control operational hazards (Granovetter, 2005; Liu et al., 2017b). Therefore, trust, timely information sharing, and open communication within relationship exchange lower the level of expost transaction costs (Gulbrandsen et al., 2017; Yigitbasioglu, 2010). Likewise, the notion of a positive relationship between sociological governance mechanisms and relationship commitment extends the view depicted in prior research (Hung \& Lin, 2013; Burkert et al., 2012). This study suggests that, based on the relational goodwill, effective communication is crucial in knowledge sharing and consistency, resulting in the resolution of conflicts and relationship commitment development (Yen et al., 2011). These findings are congruent with recent research, which suggests that trust and communication are the significant sociological factors in managing successful business relationships (e.g., Liu et al., 2017b; Gulbrandsen et al., 2017).

Second, it empirically tests the interaction effects of sociological mechanisms with contract completeness and symmetric dependence respectively in relation to ex-post transaction costs and relationship commitment. The prior research presents competing views on the nature of the relationship i.e. complementary or substitutive between governance mechanisms (e.g., Van der Valk et al., 2016; Li et al., 2010; Lee et al., 2017). This study offers additional insight and incorporates complementarity view of sociological mechanisms and symmetric dependence, and substitution view of sociological mechanisms and contract completeness. Notably, the interaction effects of trust and communication with symmetric dependence found to be complementary, 
explaining that firms can adopt these factors simultaneously in order to get cost advantages. These findings are congruent with the understanding of several authors (e.g., Dyer \& Chu 2011; Ali \& Larimo, 2016; Liu et al., 2009) who consider symmetric dependence as a form of relational governance, in which partners willingly binding them in a relationship for the purpose of social goodwill. Furthermore, the interaction effect of trust and contract completeness appeared as substitutes, explaining that firms adopt them alternatively because the presence of one obviates the use of other (Li et al., 2010; Lui \& Ngo, 2004; Wang et al., 2011; Lumineau \& Henderson, 2012). This substitution view suggests that drafting a detailed contract may be seen as counterproductive to trust and hinder the formation of sociological governance by enforcing contractual clauses, thereby increasing opportunism and transaction costs (Li et al., 2010; Wang et al., 2011). In a same fashion, Gulati and Sytch (2008) maintain that trust hinders the need of hierarchical control factors and functions as an effective alternative sociological mechanism countering opportunistic behavior. This notion posits that employing them simultaneously may complicate the understanding of inter-firm relationships, which in turn restricts the enhancement of relationship commitment. Therefore, this study suggests that contractual governance functions as substitutes with sociological governance, and can be adopted alternatively depending upon the objectives of the collaboration (Li et al., 2010; Wang et al., 2011). Instead, symmetric dependence more easily complements sociological governance because of its nature of relational embeddedness (Lee et al., 2017).

Finally, it shows the relative power of economic and sociological mechanisms on ex-post transaction costs and relationship commitment. Although both governance mechanisms drive cost advantage and commitment, their effects are different (Liu et al., 2017b; Yang et al., 2016). Our findings suggest that economic mechanisms are more powerful than sociological mechanisms in 
minimizing ex-post transaction costs. This notion elucidates that economic governance structure provides a formal framework to firms in clarifying the responsibilities and duties of relationship partners (Liu et al., 2017b) and facilitate the continuity of operations in effective manner while alleviating conflicts and additional bargaining costs more effectively than sociological structure (Yang et al., 2016; Poppo \& Zenger, 2002). However, sociological factors are more effective than economic mechanisms in maximizing relationship commitment, explaining that social factors support flexible environment and overcomes the adaptive boundaries of complex contracts, and function as informal counterforce to power imbalance inhibiting opportunistic behavior (Krause et al., 2007; Liu et al., 2009; Yang et al., 2016). This finding does not only extend our understanding of varying governance mechanisms in order to incorporate their distinguishing power but also specifies their central role in managing successful inter-firm relationships. Therefore, we argue that different governance structures are required for different transaction objectives in governing successful relationship exchange. Better understanding of relationship outcomes and collaboration goals drive managers to analyze which governance mechanism is more crucial for a particular task (Yang et al., 2016; Liu et al., 2009).

\subsection{Managerial implications}

Governing successful inter-organizational relationships requires relationship managers to show their willingness and commitment in planning and exercising the optimal governance structure, therefore, this study has several vital implications for SME managers. For this reason, firms should consider making different choices about governance mechanisms under different transaction objectives. The collaboration objectives drive managers to analyze which governance mechanism is more crucial for a particular task. Contractual governance may function as the foundation of a relationship, but relational based governance support firms to continue long-term relationships 
through cost advantage and fostered commitment. On the other hand, in the case of lack of trust between partner firms, drafting an explicitly complete contract prevents ex-post negotiations and reflects a sign of commitment, thus minimizing any possible opportunistic behavior. Further, firms are required to ensure the quality of an emplaced communication system, which reduces the possible information asymmetries and allows firms to share substantial knowledge for internal operations and external market conditions. This information sharing will protect relationship exchange from behavioral uncertainty and mitigate ex-post transaction costs, thereby keeping the firms committed. Additionally, our results suggest that symmetric dependence between firms inhibits any possible exploitation and opportunistic behavior, due to idiosyncratic investments. Managers should ensure a trustworthy relationship, which provides both partners with a certain level of confidence and align their business objectives accordingly. Another managerial implication of our study is the relative effectiveness of economic and sociological mechanisms. Our results suggest that firms seeking transaction costs advantage should pay more attention to economic governance mechanisms, whereas managers with the intention of resolving a large number of conflicts in an informal manner and develop personal ties should refer more to sociological governance mechanisms.

\subsection{Limitations and further research}

This study has some limitations that need to be addressed in further research. Firstly, drawing from the theories of TCE and SET, this study only investigates four governance mechanisms to derive the impact on ex-post transaction costs and relationship commitment. Further study may incorporate some other governance mechanisms, such as conflict resolution strategies, relational norms, uncertainty, complexity, and the reputations of partners. Noteworthy results can be found by employing individual and interaction effects of these additional governance mechanisms on 
opportunism, satisfaction, and overall relationship performance. Moreover, boundary conditions under which each of these mechanisms become more effective also ought to be investigated in future research. Secondly, this study consists of only Finnish small and medium buyer-supplier relationships, future efforts, may extend the existing Nordic SME sample in order to generalize the findings for the whole region. Thirdly, because this study represents a cross-sectional approach where only the buyer's perspective was probed in relation to governance mechanisms, it would be interesting to know how suppliers, either within a longitudinal setting or from a dyadic perspective, perceive the impact of governance mechanisms and their outcomes.

Fourthly, this study is limited to a single key informant. Future studies can obtain data from numerous but different respondents for assessing the independent and dependent constructs in order to reduce common method bias. Finally, we recommend future research in order to consider some additional issues. We encourage further research to investigate the impact of several governance mechanisms on a broad range of transaction costs (i.e., ex-ante and ex-post) as well as investigating the relationship between transaction costs and relationship commitment. Future research may also investigate the role of contingency factors on the complementary-substitution nature of economic and sociological governance mechanisms. Caniëls and Gelderman (2007) argued that a consensus regarding the optimal operationalization of interdependence lacks in the literature and resulted in contradictory findings (Kumar et al., 1995). Therefore, we also encourage researchers to advance refined measures of symmetric dependence by encompassing various aspects of dependence. Symmetric dependence may be more than the issue of symmetry and include the level of mutual dependence (i.e., high and low mutual dependence) because of the firms highly different in size (Ali \& Larimo, 2016).

\section{Acknowledgments}


This paper is an outcome of the "Suuri Yrittäjätutkimus" research project. The financial support provided by Collector Finland is also acknowledged and greatly appreciated.

\section{References}

Ali, T. \& Larimo, J. (2016). Managing opportunism in international joint ventures: the role of structural and social mechanisms. Scandinavian Journal of Management, 32 (2), 86-96.

Anderson, E. \& Weitz, B. (1992). The use of pledges to build and sustain. Journal of Marketing Research, 29, 18-34.

Armstrong, J. S., \& Overton, T. S. (1977). Estimating nonresponse bias in mail surveys. Journal of marketing research, 396-402.

Bai, X., Sheng, S., \& Li, J. J. (2016). Contract governance and buyer-supplier conflict: The moderating role of institutions. Journal of Operations Management, 41, 12-24.

Becker, J. M., Klein, K., \& Wetzels, M. (2012). Hierarchical latent variable models in PLS-SEM: guidelines for using reflective-formative type models. Long Range Planning, 45(5), 359-394.

Bharadwaj, N., \& Matsuno, K. (2006). Investigating the antecedents and outcomes of customer firm transaction cost savings in a supply chain relationship. Journal of Business research, 59(1), 62-72.

Brouthers, K. D., \& Brouthers, L. E. (2003). Why service and manufacturing entry mode choices differ: The influence of transaction cost factors, risk and trust. Journal of management studies, 40(5), 1179-1204.

Burkert, M., Ivens, B. S., \& Shan, J. (2012). Governance mechanisms in domestic and international buyer-supplier relationships: An empirical study. Industrial Marketing Management, 41(3), 544-556.

Cai, S., Yang, Z. \& Hu, Z. (2009). Exploring the governance mechanisms of quasi-integration in buyer-supplier relationships. Journal of Business Research, 62(6), 660-666.

Caniëls, M. C., \& Gelderman, C. J. (2007). Power and interdependence in buyer supplier relationships: A purchasing portfolio approach. Industrial Marketing Management, 36(2), 219-229.

Casciaro, T., \& Piskorski, M. J. (2005). Power imbalance, mutual dependence, and constraint absorption: A closer look at resource dependence theory. Administrative science quarterly, 50(2), 167-199.

Chang, S. H., Wang, K. Y., Chih, W. H., \& Tsai, W. H. (2012). Building customer commitment in business-to-business markets. Industrial marketing management, 41(6), 940-950. 
Chang, K. H. \& Gotcher, D. F. (2007). Safeguarding investments and creation of transaction value in asymmetric international subcontracting relationships: the role of relationship learning and relational capital. Journal of World Business, 42(4), 477-488.

Chang, S.-J., van Witteloostuijin, A. \& Eden, L. (2010). From the editors: common method variance in international business research. Journal of International Business Studies, 41, 178-184.

Chin, W. W. (1998). The partial least squares approach to structural equation modelling. In: G. A. Marcoulides (ed.), Modern Methods for Business Research (pp. 295-336). New Jersey: Lawrence Erlbaum Associates.

Corsten, D., \& Felde, J. (2005). Exploring the performance effects of key-supplier collaboration: an empirical investigation into Swiss buyer-supplier relationships. International Journal of Physical Distribution \& Logistics Management, 35(6), 445-461.

Crocker, K. J., \& Reynolds, K. J. (1993). The efficiency of incomplete contracts: an empirical analysis of air force engine procurement. The RAND journal of economics, 126-146.

Dahlstrom, R. \& Nygaard, A. (1999). An empirical investigation of ex post transaction costs in franchised distribution channels. Journal of Marketing Research, 36(2), 160.

Dillman, D. A., Smyth, J. D. \& Christian, L. M. (2009). Internet, Mail and Mixed-mode Surveys: The Tailored Design Method (Third Edition). New York: Wiley \& Sons.

Dyer, J. H. \& Chu, W. (2003). The role of trustworthiness in reducing transaction costs and improving performance: empirical evidence from the United States, Japan, and Korea. Organization Science, 14(1), 57-68.

Dyer, J. H. \& Chu, W. (2011). The determinants of trust in supplier-automaker relationships in the US, Japan, and Korea. Journal of International Business Studies, 42(1), 10-27.

Dyer, J. H. \& Singh, H. (1998). The relational view: cooperative strategy and sources of interorganizational competitive advantage. Academy of Management Review, 23(4), 660-679.

Dyer, J. (1997). Effective interfirm collaboration: how firms minimize transaction costs and maximize transaction value. Strategic Management Journal, 18(7), 535-556.

Gorton, M., Angell, R., Dries, L., Urutyan, V., Jackson, E., \& White, J. (2015). Power, buyer trustworthiness and supplier performance: Evidence from the Armenian dairy sector. Industrial Marketing Management, 50, 6977. 
Gotz, O., Liehr-Gobbers, K. \& Krafft, M. (2010). Evaluation of structural equation models using the partial least squares (PLS) approach. In: V. E. Vinzi, W. W. Chin, J. Henseler \& H. Wang (eds.), Handbook of Partial Least Squares: Concepts, Methods, and Applications (pp. 691-711). New York: Springer.

Granovetter, M. (2005). The impact of social structure on economic outcomes. The Journal of economic perspectives, 19(1), 33-50.

Gulati, R., \& Sytch, M. (2008). Does familiarity breed trust? Revisiting the antecedents of trust. Managerial and Decision Economics, 29(2-3), 165-190.

Gulbrandsen, B., Lambe, C. J., \& Sandvik, K. (2017). Firm boundaries and transaction costs: The complementary role of capabilities. Journal of Business Research. In press.

Hair, J. F., Sarstedt, M., Ringle, C. M., \& Mena, J. A. (2012a). An assessment of the use of partial least squares structural equation modeling in marketing research. Journal of the academy of marketing science, 40(3), 414433.

Hair, J. F., Sarstedt, M., Pieper, T. M., \& Ringle, C. M. (2012b). The use of partial least squares structural equation modeling in strategic management research: a review of past practices and recommendations for future applications. Long range planning, 45(5), 320-340.

Hawkins, T. G., Wittmann, C. M. \& Beyerlein, M. M. (2008). Antecedents and consequences of opportunism in buyersupplier relations: research synthesis and new frontiers. Industrial Marketing Management, 37(8), 895-909.

Heide, J. B. \& John, G. (1992). Do norms matter in marketing relationships? Journal of Marketing, 56(2), 32-44.

Hulland, J. (1999). Use of partial least squares (PLS) in strategic management research: a review of four recent studies. Strategic Management Journal, 20(2), 195-204.

Hung, K. P., \& Lin, C. K. (2013). More communication is not always better? The interplay between effective communication and interpersonal conflict in influencing satisfaction. Industrial Marketing Management, 42(8), 1223-1232.

Khalid, S., \& Ali, T. (2017). An integrated perspective of social exchange theory and transaction cost approach on the antecedents of trust in international joint ventures. International Business Review, 26(3), 491-501.

Kim, M., \& Chai, S. (2017). The impact of supplier innovativeness, information sharing and strategic sourcing on improving supply chain agility: Global supply chain perspective. International Journal of Production Economics, 187, 42-52. 
Kohtamäki, M., Vesalainen, J., Henneberg, S., Naudé, P. \& Ventresca, M. J. (2012). Enabling relationship structures and relationship performance improvement: the moderating role of relational capital. Industrial Marketing Management, 41(8), 1298-1309.

Krause, D. R., Handfield, R. B. \& Tyler, B. B. (2007). The relationships between supplier development, commitment, social capital accumulation and performance improvement. Journal of Operations Management, 25(2), 528545.

Kumar, N., Scheer, L. K., \& Steenkamp, J. B. E. (1995). The effects of perceived interdependence on dealer attitudes. Journal of marketing research, 348-356.

Lee, G., Shin, G. C., Haney, M. H., Kang, M., Li, S., \& Ko, C. (2017). The impact of formal control and guanxi on task conflict in outsourcing relationships in China. Industrial Marketing Management, 62, 128-136.

Li, Y., Xie, E., Teo, H. \& Peng, M. W. (2010). Formal control and social control in domestic and international buyersupplier relationships. Journal of Operations Management, 28(4), 333-344.

Liu, Y., Luo, Y. \& Liu, T. (2009). Governing buyer-supplier relationships through transactional and relational mechanisms: evidence from China. Journal of Operations Management, 27(4), 294-309.

Liu, Y., Luo, Y., Huang, Y., \& Yang, Q. (2017a). A diagnostic model of private control and collective control in buyer-supplier relationships. Industrial Marketing Management, 63, 116-128.

Liu, Y., Li, Y., Shi, L. H., \& Liu, T. (2017b). Knowledge transfer in buyer-supplier relationships: The role of transactional and relational governance mechanisms. Journal of Business Research. In press.

Lui, S. S., \& Ngo, H. Y. (2004). The role of trust and contractual safeguards on cooperation in non-equity alliances. Journal of management, 30(4), 471-485.

Lumineau, F. \& Henderson, J. E. (2012). The influence of relational experience and contractual governance on the negotiation strategy in buyer-supplier disputes. Journal of Operations Management, 30(5), 382-395.

Luo, Y. (2002). Contract, cooperation, and performance in international joint ventures. Strategic Management Journal, 23(10), 903-919.

Luo, Y. (2009). Are we on the same page? Justice agreement in international joint ventures. Journal of World Business, 44, 383-396. 
Luo, Y., Liu, Y., Yang, Q., Maksimov, V. \& Hou, J. (2015). Improving performance and reducing cost in buyersupplier relationships: the role of justice in curtailing opportunism. Journal of Business Research, 68(3), 607615.

Mitchell, R. K., Mitchell, J. R., \& Smith, J. B. (2008). Inside opportunity formation: Enterprise failure, cognition, and the creation of opportunities. Strategic Entrepreneurship Journal, 2(3), 225-242.

Mitrega, M., Forkmann, S., Zaefarian, G., \& Henneberg, S. C. (2017). Networking capability in supplier relationships and its impact on product innovation and firm performance. International Journal of Operations \& Production Management, 37(5), 577-606.

Morgan, R. M. \& Hunt, S. D. (1994). The commitment-trust theory of relationship marketing. Journal of Marketing: A Quarterly Publication of the American Marketing Association, 58(3), 20-38.

Najafi-Tavani, Z., Zaefarian, G., Naudé, P., \& Giroud, A. (2015). Reverse knowledge transfer and subsidiary power. Industrial Marketing Management, 48, 103-110.

Podsakoff, P. M., MacKenzie, S. B., Lee, J.-Y. \& Podsakoff, N. P. (2003). Common method biases in behavioral research: a critical review of the literature and recommended remedies. Journal of Applied Psychology, 88(5), 879-903.

Poppo, L. \& Zenger, T. (2002). Do formal contracts and relational governance function as substitutes or complements? Strategic Management Journal, 23(8), 707-725.

Reuer, J. J. \& Arino, A. (2002). Contractual renegotiations in strategic alliances. Journal of Management, 28(1), 4768.

Reuer, J. J., \& Ariño, A. (2007). Strategic alliance contracts: Dimensions and determinants of contractual complexity. Strategic Management Journal, 28(3), 313-330.

Ringle, C. M., Wende, S. \& Will, A. (2005). SmartPLS 2.0 (Beta). Hamburg: SmartPLS.

Sande, J. B., \& Haugland, S. A. (2015). Strategic performance effects of misaligned formal contracting: The mediating role of relational contracting. International Journal of Research in Marketing, 32(2), 187-194.

Sarstedt, M., Ringle, C. M., Henseler, J., \& Hair, J. F. (2014). On the emancipation of PLS-SEM: A commentary on Rigdon (2012). Long range planning, 47(3), 154-160.

Schmitz, T., Schweiger, B., \& Daft, J. (2016). The emergence of dependence and lock-in effects in buyer-supplier relationships-A buyer perspective. Industrial Marketing Management, 55, 22-34. 
Shen, L., Wang, Y., \& Teng, W. (2017). The moderating effect of interdependence on contracts in achieving equity versus efficiency in interfirm relationships. Journal of Business Research. In press

Shi, G., Shi, Y., Chan, A. K., Liu, M. T., \& Fam, K. S. (2011). The role of renqing in mediating customer relationship investment and relationship commitment in China. Industrial Marketing Management, 40(4), 496-502.

Silva, S. C., Bradley, F. \& Sousa, C. M. P. (2012). Empirical test of the trust-performance link in an international alliances context. International Business Review, 21(2), 293-306.

Tellefsen, T. (2002). Commitment in business-to-business relationships: the role of organizational and personal needs. Industrial Marketing Management, 31(8), 645-652.

Van der Valk, W., Sumo, R., Dul, J., \& Schroeder, R. G. (2016). When are contracts and trust necessary for innovation in buyer-supplier relationships? A Necessary Condition Analysis. Journal of Purchasing and Supply Management, 22(4), 266-277.

Villena, V. H., Revilla, E., \& Choi, T. Y. (2011). The dark side of buyer-supplier relationships: A social capital perspective. Journal of Operations management, 29(6), 561-576.

Wang, L., Yeung, J. H. Y., \& Zhang, M. (2011). The impact of trust and contract on innovation performance: The moderating role of environmental uncertainty. International Journal of Production Economics, 134(1), 114122.

Wang, Y., Wang, N., Jiang, L., Yang, Z., \& Cui, V. (2016). Managing relationships with power advantage buyers: The role of supplier initiated bonding tactics in long-term buyer-supplier collaborations. Journal of Business Research, 69(12), 5587-5596.

Williamson, O. E. (1985). The Economic Institutions of Capitalism: Firms, Markets, Relational Contracting. New York: The Free Press.

Williamson, O. E. (1993a). Calculativeness, trust, and economic organization. The Journal of Law and Economics, 36(1, Part 2), 453-486.

Woolthuis, R. K., Hillebrand, B. \& Nooteboom, B. (2005). Trust, contract and relationship development. Organization Studies, 26(6), 813-840.

Wu, J., \& Wu, Z. (2015). Key supplier relationships and product introduction success: The moderating roles of selfenforcement and interdependence between buyer and supplier. Industrial Marketing Management, 46, 183192. 
Wuyts, S. \& Geyskens, I. (2005). The formation of buyer-supplier relationships: detailed contract drafting and close partner selection. Journal of Marketing, 69(4), 103-117.

Yang, Q., Zhao, X., Yeung, H. Y. J., \& Liu, Y. (2016). Improving logistics outsourcing performance through transactional and relational mechanisms under transaction uncertainties: Evidence from China. International Journal of Production Economics, 175, 12-23.

Yang, W., Gao, Y., Li, Y., Shen, H., \& Zheng, S. (2017). Different roles of control mechanisms in buyer-supplier conflict: An empirical study from China. Industrial Marketing Management, in press.

Yen, Y. X., Shih-Tse Wang, E., \& Horng, D. J. (2011). Suppliers' willingness of customization, effective communication, and trust: a study of switching cost antecedents. Journal of Business \& Industrial Marketing, 26(4), 250-259.

Yigitbasioglu, O. M. (2010). Information sharing with key suppliers: a transaction cost theory perspective. International Journal of Physical Distribution \& Logistics Management, 40(7), 550-578.

Young-Ybarra, C. \& Wiersema, M. (1999). Strategic flexibility in information technology alliances: the influence of transaction cost economics and social exchange theory. Organization Science, 10(4), 439-459.

Zaheer, A., McEvily, B. \& Perrone, V. (1998). Does trust matter? Exploring the effects of interorganizational and interpersonal trust on performance. Organization Science, 9(2), 141-159.

Zaefarian, G., Forkmann, S., Mitręga, M., \& Henneberg, S. C. (2017). A capability perspective on relationship ending and its impact on product innovation success and firm performance. Long Range Planning, 50(2), 184-199.

Zeng, M. (1998). The Impact of Structure on Cooperation and Performance in Joint Ventures: An Empirical Investigation of International Joint Ventures. Doctoral dissertation. Urbana-Champaign: University of Illinois. 